\title{
Prevalence of inclusion body hepatitis (IBH) in Poland from 2010-2014
}

\author{
A. Gawet ${ }^{1}$, M. Nowak ${ }^{2}$, R. Ciaputa ${ }^{2}$, K. Bobrek ${ }^{1}$ \\ ${ }^{1}$ Department of Epizootiology and Clinic of Bird and Exotic Animals, Faculty of Veterinary Medicine, \\ Wrocław University of Environmental and Life Sciences, pl. Grunwaldzki 45, 50-355 Wrocław, Poland \\ ${ }^{2}$ Department of Pathology, Faculty of Veterinary Medicine, \\ Wrocław University of Environmental and Life Sciences, ul. C.K. Norwida 31; 50-375 Wrocław, Poland
}

\begin{abstract}
This study investigated the prevalence of inclusion body hepatitis (IBH) infections during the past five years (2010-2014) in broiler chicken flocks in Poland. The diagnosis of IBH was based on anatomopathological investigations and histopathological analyzes. IBH was the most prevalent disease in broiler flocks in Poland (10.4\%) during this time period, and occurred as a primary infection. The fewest cases of IBH occurred in the summer, suggesting that the temperature may have been a possible stressor that increased susceptibility to IBH. However, over the last 5 years the occurrence of clinical IBH cases in Poland has systematically decreased.
\end{abstract}

Key words: inclusion body hepatitis (IBH), chickens, Poland

\section{Introduction}

Inclusion body hepatitis (IBH) is an emerging pathogen that has economic significance for the global chicken industry (Gomis et al. 2006, Ojkic et al. 2008, Nakamura et al. 2011). IBH is an acute, viral infection that affects broiler chickens between 2 and 7 weeks of age. The disease manifests suddenly, has a short clinical course (4-5 days), and is associated with increased mortality rates generally from $1-20 \%$ (Gomis et al. 2006, Nakamura et al. 2011), but occasionally exceeding 30-40\% (Erny et al. 1991). Infected chickens typically have pale, friable, swollen livers with focal to extensive necrosis, and large basophilic inclusion bodies in hepatocytes (Reece et al. 1986). The pathogenesis of IBH is not clearly understood as it is influenced by multiple factors including the host, pathogen, toxins and the environment (Erny et al. 1991, Mendelson et al. 1995, Singh et al. 1996, Gomis et al. 2006). Currently, infection with fowl adenovirus (FAdV) is the primary cause of IBH. In Poland, FAdV infection was confirmed in over $12 \%$ of analyzed samples, but in most cases liver gross lesions were not observed (Niczyporuk et al. 2013). As the epidemiology of IBH has not been studied in Poland to date, this study was conducted to evaluate the prevalence of IBH in Polish flocks.

\section{Materials and Methods}

The study was carried out using tissue samples collected for histopathological examination by pri- 
Table 1. Number of IBH positive samples by month and year.

\begin{tabular}{|c|c|c|c|c|c|c|c|c|c|c|c|c|}
\hline \multirow{3}{*}{ Month } & \multicolumn{10}{|c|}{ Year } & \multirow{2}{*}{\multicolumn{2}{|c|}{ Total }} \\
\hline & \multicolumn{2}{|c|}{2010} & \multicolumn{2}{|c|}{2011} & \multicolumn{2}{|c|}{2012} & \multicolumn{2}{|c|}{2013} & \multicolumn{2}{|c|}{2014} & & \\
\hline & IBH & All* & IBH & All & IBH & All & IBH & All & IBH & All & IBH & All \\
\hline January & & 5 & 1 & 2 & 3 & 22 & 3 & 20 & & 10 & $7(11.9 \%)$ & 59 \\
\hline February & & 5 & 2 & 2 & 3 & 13 & 1 & 16 & & 9 & $6(13.3 \%)$ & 45 \\
\hline March & 3 & 14 & 3 & 9 & 3 & 29 & 3 & 17 & 1 & 23 & $13(14.1 \%)$ & 92 \\
\hline April & 3 & 16 & 4 & 15 & & 11 & 3 & 22 & & 15 & $10(12.6 \%)$ & 79 \\
\hline May & 3 & 5 & 7 & 22 & 2 & 12 & 2 & 29 & & 23 & $14(15.4 \%)$ & 91 \\
\hline June & 1 & 8 & 7 & 24 & 1 & 22 & & 12 & 1 & 9 & $10(13.3 \%)$ & 75 \\
\hline July & 1 & 10 & & 3 & 1 & 9 & & 9 & & 13 & $2(4.5 \%)$ & 44 \\
\hline August & 2 & 8 & & 31 & & 6 & & 11 & & 12 & $2(2.9 \%)$ & 68 \\
\hline September & & 12 & 1 & 15 & & 6 & 1 & 13 & 1 & 15 & $3(4.9 \%)$ & 61 \\
\hline October & 1 & 3 & 1 & 25 & 2 & 19 & 1 & 10 & & 21 & $5(6.4 \%)$ & 78 \\
\hline November & & 3 & 3 & 15 & 3 & 37 & & 7 & 2 & 14 & $8(10.5 \%)$ & 76 \\
\hline December & 1 & 1 & & 10 & 3 & 14 & & 14 & & 10 & $4(10.2 \%)$ & 39 \\
\hline Total & $\begin{array}{c}15 \\
(16.7 \%)\end{array}$ & 90 & $\begin{array}{c}29 \\
(16.9 \%)\end{array}$ & 172 & $\begin{array}{c}20 \\
(10.0 \%)\end{array}$ & 200 & $\begin{array}{c}14 \\
(7.8 \%)\end{array}$ & 180 & $\begin{array}{c}5 \\
(2.9 \%)\end{array}$ & 174 & $\begin{array}{c}85 \\
(10.4 \%)\end{array}$ & 816 \\
\hline
\end{tabular}

* All indicates the total number of broiler chickens tested

Table 2. Number of IBH cases by age and concurrent disease.

\begin{tabular}{ccc}
\hline Weeks of life & Total number of cases & Other diagnosed health problems \\
\hline 1 & 1 & Bacterial infection \\
\hline 2 & 16 & \\
\hline 3 & 16 & Marek disease \\
\hline 4 & 25 & IB, Bacterial infection $(2 x)$ \\
\hline 5 & 18 & Bacterial infection $(4 x)$ \\
\hline 6 & 8 & Bacterial infection, reovirus
\end{tabular}

* production cycle was prolonged because of low body weight in the flock

vate-practice veterinarians between 2010 and 2014 from commercial flocks (>20,000 birds/flock) of broiler chickens from Poland at the Department of Pathology, Wroclaw University of Environmental and Life Sciences. The tissues analyzed included the liver, kidney, spleen, heart, lung, bursa of Fabricius, gizzard, proventriculus, pancreas, duodenum, and ileum. The samples were fixed in $7 \%$ buffered formalin for 24 hours, embedded in paraffin, and cut into $4 \mu \mathrm{m}$ sections. The sections were stained using hematoxylin and eosin. Microphotographs of the samples were analyzed using computer-assisted image analysis with an Olympus BX53 (Olympus, Japan) optical microscope. All measurements were performed using cell^ software (Olympus Soft Imaging Solution $\mathrm{GmbH}$, Germany).

\section{Results and Discussion}

Over a 5-year period, histopathological examinations were performed on 816 samples from commercial broiler flocks in Poland (Table 1). IBH was generally confirmed retrospectively by histopathological examination by the presence of typical lesions, including basophilic intranuclear inclusion bodies, necrosis, congestion, and blood stagnation in the liver. Of the 816 samples, $85(>10 \%)$ were classified as IBH positive. The high frequency of IBH infection makes it the most prevalent disease in commercial broiler chicken flocks in western Poland. This is also consistent with a high rate $(29 \%)$ of microscopic liver lesions typical of IBH reported by Dolka et al. (2012) in samples obtained from birds between 1999 and 2010. The age 
of IBH positive chickens ranged from 1 to 7 weeks, but the highest prevalence was observed in the $4^{\text {th }}$ week of life (Table 2). This is consistent with published data from other authors (Singh et al. 1996, Nakamura et al. 2011, Dolka et al. 2012, Niczyporuk et al. 2013). In the samples from broiler chickens that were in their $2^{\text {nd }}$ and $3^{\text {rd }}$ week of life IBH seemed to be a primary infection. In older birds, other viral and bacterial infections were diagnosed simultaneously. Historically, IBH has been identified as a secondary disease, often associated with common immunosuppressive diseases such as infections bursal disease, Mareks disease, chronic respiratory disease, airsacculitis, rickets, coryza, coccidiosis, encephalomalacia, and vitamin A deficiency (Fadly et al. 1976, Singh et al. 1996, Niczyporuk et al. 2013). However, a small number of studies have identified IBH as a primary disease that has no apparent association with immunosuppressive diseases (Christensen and Saifuddin 1989, Gomis et al. 2006). An alternative cause for IBH outbreaks may be related to stress. We found the fewest number of IBH cases $(15 \%)$ were diagnosed from July to October, when temperatures in Poland are high (usually $>20^{\circ} \mathrm{C}$ ) and there are no large, rapid decreases in the temperature. In contrast, in the autumn, winter, and spring there are large variations in temperatures between the months, and in some months temperatures vary widely between the day and night. A similar observation regarding the concurrence of IBH infection and the seasons was also noted by Mittal et al. (2014) in Pakistan. Mittal et al. noted that a larger number of broiler flocks were affected with IBH in the winter and rainy seasons. In addition, most outbreaks in India $(>50 \%)$ were recorded during October, November, and December when the temperatures are the coolest, decreasing by approximately $5^{\circ} \mathrm{C}$ per month. The authors also demonstrated a correlation between the large number of outbreaks during these months and the temperatures and relative humidity each month; they suggest that high levels of mycotoxins may be an indicator of IBH (Singh et al. 1996). Niczyporuk et al. (2013) have shown that the number of FAdV infections occurring each year in Poland has been increasing. In contrast, our data shown that the number of clinical IBH cases has decreased (Table 1), which may be the result of high quality of flock management to ensure optimal living conditions for the birds.

\section{References}

Christensen NH, Saifuddin M (1989) A primary epidemic of inclusion body hepatitis in broilers. Avian Dis 33: 622-630.

Dolka I, Sapierzyński R, Bielecki W, Malicka E, Zbikowski A, Szeleszczuk P (2012) Histopathology in diagnosis of broiler chicken and layer diseases--review of cases 1999-2010. Pol J Vet Sci 15: 773-779.

Erny KM, Barr DA, Fahey KJ (1991) Molecular characterization of highly virulent fowl adenoviruses associated with outbreaks of inclusion body hepatitis. Avian Pathol 20: 597-606.

Fadly AM, Winterfield RW, Olander HJ (1976) Role of the bursa of Fabricius in the pathogenicity of inclusion body hepatitis and infectious bursal disease viruses. Avian Dis 20: 467-477.

Gomis S, Goodhope AR, Ojkic AD, Willson P (2006) Inclusion body hepatitis as a primary disease in broilers in Saskatchewan, Canada. Avian Dis 50: 550-555.

Mendelson C, Nothelfer HB, Monreal G (1995) Identification and characterization of an avian adenovirus isolated from a :spiking mortality syndrome; field outbreak in broilers on the Delmarva Peninsula, USA. Avian Pathol 24: 693-706.

Mittal D, Jindal N, Khokhar RS (2014) Epidemiological studies on inclusion body hepatitis hydropericardium syndrome in broiler chicken in Haryana State Haryana Vet 53: $34-38$

Nakamura K, Mase M, Yamamoto Y, Takizawa K, Kabeya M, Wakuda T, Matsuda M, Chikuba T, Yamamoto Y, Ohyama T, Takahashi K, Sato N, Akiyama N, Honma H, Imai $K$ (2011) Inclusion body hepatitis caused by fowl adenovirus in broiler chickens in Japan, 2009-2010. Avian Dis 55: 719-723.

Niczyporuk J, Samorek- Salamonowicz E, Czekaj H (2013) Analysis of adenovirus strains isolated from poultry in Poland. Bull Vet Inst Pulawy 57: 305-310.

Ojkic D, Martin E, Swinton J, Vaillancourt JP, Boulianne M, Gomis S (2008) Genotyping of Canadian isolates of fowl adenoviruses. Avian Pathol 37: 95-100.

Reece RL, Barr DA, Grix DC, Forsyth WM, Condron RJ, Hindmarsh M (1986) Observations on naturally occuring inclusion body hepatitis in Victorian chickens. Aust Vet J 63: 201-202.

Singh A, Oberoi MS, Jand SK, Singh B (1996) Epidemiology of inclusion body hepatitis in poultry in northern India from 1990 to 1994. Rev Sci Tech 15: 1053-1060. 